ISSN (Online): 2621-0851

Volume 1, Nomor 1, Mei 2018

\title{
REGISTER DALAM INTERAKSI WARIA DI KABUPATEN LOMBOK TIMUR
}

\author{
Melisa Fitriyah ${ }^{1}$, Muh. Ardian Kurniawan ${ }^{2}$ \\ SMP Negeri 1 Sakra Barat ${ }^{1}$; Universitas Timor ${ }^{2}$ \\ Pos-el: melishaafitriyah@gmail.com; muhardika88@yahoo.co.id
}

\begin{abstract}
This study aimed to describe the transgender language registers in East Lombok regency, in accordance with the problems: (a) the form of the language registers used by transgender, (b) the meaning of the transgender language register, (c) the function of the use of the transgender language register. This type of research uses descriptive qualitative research. Techniques of data collection is done by tapping technique, consider involve ably, and record. While the data analysis technique is done by reviewing data, classifying data, analysis and drawing conclusions. Data validity is obtained by triangulation of data. Based on the results of the analysis of the registers in the interaction of transgender language in East Lombok regency, can be drawn conclusion that is: first, the form of transgender language registers can be classified into two that is besed on source and relationship. Second, the meaning of the transgender language registers include between words interpreted with meaningful words. The word is interpreted as a word used to express the intention, while the word meaning is the word that became the intent. as in the word "Dendong $><$ Dandan" word grooming and dangled with the word dendong and dendong word meaning word grooming. Third, the function of the use of transgender language registers are self and group identity, attitude change, pride and confidence.
\end{abstract}

Keywords: form, meaning, and function, transgender language register.

\begin{abstract}
Abstrak
Penelitian ini mengambil topik tentang register bahasa waria di Kabupaten Lombok Timur. Adapun tujuan penelitian ini adalah untuk mendeskripsikan (a) bentuk register bahasa yang digunakan oleh kaum waria, (b) makna register bahasa waria, (c) fungsi penggunaan register bahasa waria. Jenis penelitian ini menggunakan penelitian kualitatif deskriptif. Teknik pengumpulan data dilakukan dengan teknik sadap, simak libat cakap, dan catat. Sedangkan teknik analisis data dilakukan dengan menelaah data, mengklasifikasikan data, analisis dan penarikan simpulan. Keabsahan data diperoleh dengan triangulasi data. Berdasarkan hasil analisis tentang register dalam interaksi bahasa waria di Kabupaten Lombok Timur, dapat ditarik simpulan yaitu: pertama, bentuk register bahasa waria dapat diklasifikasikan menjadi dua yaitu berdasarkan sumber dan hubungan. Kedua, makna register bahasa waria meliputi antara kata yang dimaknai dengan kata yang memaknai. Kata yang dimaknai sebagai kata yang digunakan untuk mengungkapkan maksud, sedangkan kata yang memaknai adalah kata yang menjadi maksud, seperti pada kata Dendong $><$ Dandan kata dandan dimakanai dengan kata dendong dan kata dendong memaknai kata dandan. Ketiga, fungsi penggunaan register bahasa waria yaitu sebagai identitas diri dan kelompok, perubahan sikap, menumbuhkan rasa bangga dan percaya diri. Kata Kunci: bentuk, makna dan fungsi, register bahasa waria.
\end{abstract}

\section{PENDAHULUAN}

Komunikasi terjadi apabila adanya kegiatan interaksi sosial yang dilakukan oleh sekelompok orang. Bahasa sebagai sarana komunikasi dapat menyebarkan berbagai macam informasi dikarenakan bahasa sangat besar kaitannya dengan masyarakat. Variasi bahasa 
berdasarkan penggunaannya, pemakaiannya, atau fungsinya lazim disebut dengan register. Dalam register bahasa sendiri digunakan berkenaan dengan keperluan atau kegiatan apa dan bidang apa.

Komunitas waria merupakan fenomena unik dan menarik yang terlihat di masyarakat saat ini. Sebagian dari mereka memiliki profesi sebagai pekerja salon, penata rias/kecantikan, penata rambut, dan ada juga yang berprofesi menjadi penyanyi. Seperti halnya dengan komunitas waria yang ada di Kabupaten Lombok Timur yang kebanyakan dari mereka menjadi pekerja salon atau penyayi. Kaum waria berperilaku dan berpenampilan layaknya seorang perempuan. Sering juga beberapa dari mereka memiliki ketertarikan dengan sesama jenis yang biasa kita kenal dengan sebutan homoseksual. Kesadaran masyarakat saat ini dengan keberadaan waria masih sangat terbatas karena masyarakat masih menganggap waria sebagai orang yang aneh. Waria sering diejek, dicemooh, dikucilkan atau dijauhi, serta mereka mendapatkan perlakuan diskriminatif yang lain dari masyarakat sekitarnya, sehingga banyak dari mereka yang lari dan meninggalkan kampung halamannya untuk membentuk komunitas sendiri sesama waria. Dengan latar belakang itu, kaum waria memiliki bahasa tersendiri atau bahasa khusus yang hanya diketahui oleh komunitasnya saja.

Pemilihan Kabupaten Lombok Timur sebagai lokasi penelitian menjadi sangat penting. Sebab, secara kultural, Kabupaten Lombok Timur dikenal memiliki masyarakat dengan kultur agama yang kuat. Di sana, mengakar kuat ajaran Islam dengan organisasi Nahdlatul Wathan (NW) sebagai motornya. Kedua organisasi ini memiliki basis massa di wilayah Pancor dan Anjani, meskipun pada kenyataannya NW sudah menyebar ke seluruh Pulau Lombok. Secara historis, Kabupaten Lombok Timur juga memiliki loyalitas yang kuat pada ajaran Islam dengan sentimen yang tinggi dengan pemeluk agama lain. Islam sudah menjadi agama dan budaya sekaligus bagi mayoritas masyarakat di Pulau Lombok. Kasus kerusuhan SARA yang sempat terjadi pada tahun 2000 awal di Pulau Lombok juga berimbas pada berhati-hatinya komunitas agama atau kepercayaan lain yang berbeda secara signifikan dengan Islam. Meskipun saat ini kondisi sudah membaik, trauma tentu masih sangat membekas bagi mereka yang menjadi korban. Mengapa ini penting untuk disampaikan? Komunitas waria merupakan komunitas yang masih tergolong "kelompok terlarang/tabu" di kalangan masyarakat umum. Kehadiran mereka tentunya akan menyebabkan gangguan/disharmonisasi dan ketidakseimbangan dalam tatanan sosial masyarakat. Pertentangan ini membuat komunitas tutur waria untuk menyiasati agar eksistensi mereka tetap bisa berjalan tanpa diketahui oleh kelompok lainnya yang cenderung bersifat reaktif terhadap mereka.

Register merupakan salah satu jenis variasi bahasa dilihat berdasarkan kebutuhan pemakaian bahasa. Menurut Pateda (1992: 64), register merupakan "pemakaian bahasa yang dihubungkan dengan pekerjaan seseorang". Pendapat Pateda ini sejalan dengan pemikiran Sumarsono (2012). Namun, dalam pemahaman Holmes (1992), register lebih dilihat menyerupai gaya (style) yang digunakan karena faktor konteksnya. Dalam hal ini, konteks bisa berupa banyak hal, baik jenis kelamin, status sosial, suku, agama, pekerjaan, ataupun ikatan kelompok. Dalam hal yang terakhir ini, komunitas waria patut diperhatikan karena 
pada dasarnya komunitas ini dibangun berdasarkan faktor sosial yang menjadi perlambang identitas dan ikatan sosial mereka.

Waria (singkatan dari wanita pria) atau wadam (wanita Adam atau Hawa Adam) merujuk kepada orang-orang yang secara biologis atau fisik berkelamin laki-laki, tetapi berpenampilan (berpakaian atau berdandan) serta berperilaku seperti atau mengidentifikasikan diri sebagai perempuan. Berdasarkan hal di atas, register bahasa waria di Kabupaten Lombok Timur menarik untuk didiskusikan, terutama dalam hal (a) bentuk register bahasa yang digunakan oleh kaum waria, (b) makna register bahasa waria, (c) fungsi penggunaan register bahasa waria.

Secara sistematis, artikel ini disajikan sesuai dengan urutan sebagai berikut. Pada bagian awal disampaikan latar belakang masalah yang berisi argumentasi pendukung topik, rumusan masalah, dan teori yang berkaitan dengan topik bahasan pada artikel ini. Selanjutnya, dipaparkan metode penelitian. Hasil penelitian dan pembahasan didiskusikan pada bagian berikutnya. Pembahasan berfokus pada upaya menjawab rumusan masalah yang sudah disampaikan sebelumnya. Bagian akhir artikel ini berisi simpulan atas hasil penelitian dan pembahasan.

\section{METODE PENELITIAN}

Metode penelitian yaitu cara untuk mendapatkan data. "Metodelogi penelitian pada umumnya diartikan sebagai cara ilmiah untuk mendapatkan data dengan tujuan dan kegunaan tertentu" (Sugiyono, 2013: 3). Untuk pemahaman secara mendalam terhadap permasalahan yang telah terumuskan dan pemerolehan data yang akurat dan tepercaya, penulis menggunakan strategi atau langkah-langkah di antaranya: menetapkan lokasi penelitian, bentuk dan strategi penelitian, sumber data, teknik pengumpulan data, (sadaprekam, simak libat cakap, dan catat), teknik analisis, dan prosedur kegiatan.

Kemudian dalam penelitian ini, penulis menggunakan jenis penelitian deskriptif kualitatif yang lebih mengarah kepada penelitian analisis dokumen atau analisis isi, sebab jenis penelitian ini sesuai dengan jenis penelitian yang dibutuhkan dalam meneliti, yaitu penelitian yang dilakukan secara sistematis terhadap catatan-catatan atau dokumen sebagai sumber data yang diperoleh dari hasil rekaman, gambar atau sebagainya.

Data yang digunakan dalam penelitian ini adalah data kualitatif yang dikelompokan menjadi dua macam, yaitu data primer dan data skunder. Data primer berupa data lisan yang diambil melalui hasil sadap rekam berupa kosakata yang diucapkan waria yang sedang melakukan interaksi antarsesamanya. Data sekunder dalam penelitian ini diambil dari hasil simak libat cakap dengan waria mengenai dialog/interaksi yang mereka lakukan serta beberapa dokumen dan referensi yang berkaitan dengan penelitian ini.

Analisis data dilakukan secara deskriptif yaitu dengan menggunakan kata-kata biasa yang apabila dibaca mudah dipahami maksudnya. Analisis deskriptif dapat dijabarkan sebagai berikut.

1. Menguraikan bentuk jumlah kosakata register bahasa waria yang terjadi dalam dialog/interaksi waria.

2. Selama meneliti, penulis lebih banyak berinteraksi dengan komunitas waria yang sedang ditelitinya. 
3. Penulis mencatat dan merekam berbagai bentuk tuturan lisan untuk dianalisis.

4. Seluruh data yang diperoleh melalui melihat, mencatat, berbicara, dan mendengar akan ditelaah secara mendalam.

5. Setelah data yang diperlukan untuk analisis terkumpul, tahap selanjutnya yang ditempuh adalah tahap analisis data. Analisis data register bahasa waria dilakukan dengan mengamati secara cermat kosakata bahasa waria. Data kosakata bahasa waria yang diperoleh kemudian ditentukan klasifikasinya dan makna kosakatanya. Setelah itu menjabarkan fungsi penggunaan register bahasa waria.

\section{HASIL PENELITIAN DAN PEMBAHASAN}

Pada bagian ini akan dipaparkan hasil penelitian terkait dengan register bahasa waria yang telah dijabarkan pada bagian pendahuluan.

\section{Bentuk dan Makna Register Bahasa Waria}

Bentuk penggunaan register dalam bahasa waria memiliki klasifikasi kosakata berdasarkan sumber, hubungan, dan jenisnya, hal itu dapat dilihat pada data berikut.

\section{a. Bentuk klasifikasi register bahasa waria berdasarkan sumber}

1. Penggunaan kosakata bahasa waria bersumber dari nama/kata ganti orang.

a) maya [maya] : 'berhubungan seks'

b) handika [handika] : 'handuk'

c) sinyorita [siñorita] : 'mencari'

d) marsandha [marsanda] : 'marah'

e) sakinah [sakinah] : 'sakit'

f) sundari [sundari]: 'sundel'

g) brama kumbara [brama kumbara]: 'minuman keras’

h) harmain [harmain]: 'harum'

i) putri [putri]: 'putih'

Pada data di atas terlihat adanya keterkaitan penggunaan nama/kata ganti orang dalam pembentukan register bahasa waria. Hal serupa dapat diartikan bahwa register bahasa waria secara bentuk kebahasaan tidak memiliki tatanan yang utuh, atau dapat dikatakan kaum waria membentuk tatanan kebahasaan secara sewenangwenang dan hanya dimengerti oleh sesamanya atau di kalangan komunitasnya. Dalam kalimat dapat dilihat contoh percakapan bahasa waria berikut ini.

A : "akika sakinah hetong sama diana, tinta kasih kabar kalau ke luar." (aku sakit hati dengan dia tidak kasih kabar kalau ke luar).

E : "sabar ciiin." (sabar sayang).

2. Penggunaan kosakata bahasa waria bersumber dari nama binatang

a) cumi-cumi [cumi-cumi]: 'ciuman'

b) tupai [tupai]: 'tutup'

c) belalang [b lalan]: 'beli' 
Data di atas masih berkaitan dengan penggunaan nama, jika dalam penggunaan kalimat maka akan seperti “akika mawar belalang tisu." (saya mau beli tisu). Namun hal serupa juga terkait dengan nama binatang yang hal itu dapat memepengaruhi pembentukan kosakata dalam register bahasa waria.

3. Penggunaan kosakata bahasa waria bersumber dari nama iklan secara umum
a) masako [masako] : 'masak'
b) rexona [r ksona] : 'rokok'
c) panasonic [panasכnik]: 'panas'
d) pepsi [p psi]: 'vagina'
e) hitaci [hitaci]: 'hitam'

Sealain digunakannya nama orang dan binatang dalam pembentukan kosa kata register bahasa waria, disamping itu juga mereka menambahakan dengan nama produk atau iklan secara umum berdasarkan dari kesepakatan diantara mereka. Jika dalam penggunaan kalimat seperti berikut: “cin belalang rexona dong?" (sayang beli rokok dong?).

4. Penggunaan kosakata waria bersumber dari nama tempat/geografis
a) makasar [makasar]: 'makan'
b) mataram [mataram]: 'mata'
c) minahasa [minahasa]: 'minum'
d) ambarawa [ambarawa]: 'ambil'

Data di atas membuktikan bahwa pembentukan kosa kata register bahasa waria tidak hanya terpaku pada satu lingkup nama saja, namun juga berkaitan dengan nama tempat atau geografis, tergantung dari kecocokan setiap makna dari kata yang diucapkan contoh dalam percakapan berikut: “adinda sutra makasar?” (dik sudah makan?).

5. Penggunaan kosakata bahasa waria bersumber dari nama bunga.

a) mawar [mawar]: 'mau'

Misalnya saja pada percakapan berikut. "kapan adinda mawar cuncang banjaran?" (kapan adik mau nyuci baju?).

6. Penggunaan kosakata bahasa waria bersumber dari makanan.

a) nasbro [nasbro] : 'nasi'

b) capcai [capcai]: 'cepetan'

c) bawang goreng [bawa nor $\eta]$ : 'bau'

7. Penggunaan kosakata bahasa waria bersumber dari pangkat/jabatan seseorang.

a) Komisaris [komisaris]: 'kumis'

\section{a. Bentuk klasifikasi register bahasa waria berdasarkan hubungan}


1. Penggunaan kosakata bahasa waria berhubungan dengan panggilan sayang.
a) ibunda [ibunda] : 'ibu'
b) kakanda [kakanda] : 'kakak'
c) adinda [adinda] : 'adik'
d) cantika [cantika] : 'cantik'

Data di atas menunjukkan bahwa waria yang dituakan atau waria yang dijadikan panutan akan memiliki panggilan sayang oleh waria yang lain, bahkan terhadap waria yang baru bergabung memiliki panggilan sayang karena rasa saling menghargai yang tercipta oleh sesama waria seperti data di atas.

2. Penggunaan kosakata bahasa waria berhubungan dengan jenis kelamin.
a) pewong [p won] : 'cewek'
b) lekong [1 koฑ] : 'cowok'

3. Penggunaan kosakata bahasa waria berhubungan dengan pesan seseorang.

a) hetong-hetong [h to $\eta$-h ton]: 'hati-hati'

4. Penggunaan kosakata bahasa waria berhubungan dengan kondisi tubuh.
a) pus-pus [pus-pus] : 'pusing'
b) dindong [dindon] : 'dingin'
c) bersinah [b rsinah] :'bersih'
d) kotorep [kotכr p] : 'kotor'

5. Penggunaan kosakata bahasa waria berhubungan dengan perilaku negatif.
a) nyebong [ñ bo $]$ : 'kelayapan/mangkal'
b) maloling [malolin]: 'maling'

6. Penggunaan kosakata bahasa waria berhubungan dengan perasaan.
a) senandung [senandun] : 'senang'
b) sukria [sukria] : 'suka'
c) marsandha [marsandha] : 'marah'

7. Penggunaan kosakata bahasa waria berhubungan dengan sifat seseorang.

a) cerewolet $\left[\begin{array}{cccc}c & r & \text { wol t }\end{array}\right]$ : 'cerewet'

b) jahara [jahara] : 'jahat'

c) jelitur [j litur] : 'jelek'

8. Penggunaan kosakata bahasa waria berhubungan dengan pernyataan diri.

a) akika [akika]: 'aku'

9. Penggunaan kosakata bahasa waria berhubungan dengan anggota tubuh.
a) kekong [k kon] : 'kaki'

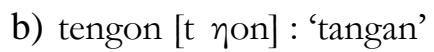
c) gegong [g gon] : gigi
d) peruca $[\mathrm{p}$ ruca]: 'perut'
e) patroli [patroli]: 'pantat'
f) rembongan [r mbonan] : 'rambut'
g) kepelong [k p lon] : 'kepala'
h) sensong [s nson] : payudara 
i) kendi [k ndi]: 'venis'

j) Pepsi [p psi] : 'vagina'

10.Penggunaan kosakata bahasa waria berhubungan dengan pakaian.

a) banjaran [banjaran] : 'baju'

b) celenong [c 1 noฑ] : 'celana'

c) beholet [b holet] : 'bh/bra'

d) tesong [t son]: 'tas'

e) sandolep [sandol p]: 'sandal'

f) sepetong [s p ton] : 'sepatu'

11.Penggunaan kosakata bahasa waria berhubungan dengan pernyataan penegasan.

a) sutra [sutra] : 'sudah'

b) tinta [tinta] : 'tidak'

12.Penggunaan kosakata bahasa waria berhubungan dengan warna.

a) merana [m rana]: 'merah'

b) hijolet [hijol t] : 'hiijau'

c) kuningsih[kuninsih] : 'kuning'

d) hitaci [hitaci] : 'hitam'

13.Penggunaan kosakata bahasa waria berhubungan dengan benda.

a) motorola [motวrola] : 'motor'

b) hepes [h p s]: 'handephone'

c) rungkit [runkit] : 'rumah'

14.Penggunaan kosakata bahasa waria berhubungan dengan kegiatan seharihari.

a) dadakan [dadakan] : 'duduk'

b) ngoprok [noprok] : 'ngopi'

c) tidarsa [tidarsa] : 'tidur'

d) kencana [k ncana] : 'kencing'

e) mandira [mandira] : 'mandi'

f) cuncang [cuncan] : 'nyuci'

g) tahitong [tahiton] : 'buang air besar'

h) jejong $[\mathrm{j}$ jon] : 'jajan’

i) dendong [d ndon] : 'dandan'

j) jelong-jelong [j lon- j lon] : ‘jalan-jalan’

k) liliput [liliput] : 'lihat'

15.Penggunaan kosakata bahasa waria berhubungan dengan hal-hal lain.
a) bungolet [bunol t] : 'bunga'
b) potenggo [pot $\eta g o]$ : 'foto'
c) pekong [p kon] : 'pakai'
d) pecongan [p conan] : 'pacaran'
e) air manior [air manior] : 'air' 
f) peges [p g s] : 'pegang'

g) rombongan mataram [rombonan mataram] : 'bulu mata'

h) ngereyong $[\eta \mathrm{r}$ yo $\eta]$ : 'ngerayu'

i) bala-bala [bala-bala] : 'minta'

j) organda [organda]: 'orang'

k) bukria [bukria]: 'buka'

l) kesindang [kesindan] : 'kesini'

m) kasma [kasma] : 'kasih dia'

n) ojeka [ojeka] : 'ojek'

o) kawinah [kawinah] : 'kawin'

p) sapose [sapos ]: 'siapa'

q) banjar [banjar] : 'banyak'

r) mukria [mukria] : 'muka'

Data di atas menunjukkan masih banyak bentuk penggunaan register bahasa waria secara umum dan tidak mengacu kepada satu jenis, bentuk, dan satu sumber saja. Namun juga dapat bersumber maupun berhubungan pada hal lain berdasarkan dari aktifitas dan profesi mereka.

Pemaknaan dalam bahasa waria tidak sama dengan pemaknaan dalam bahasa Indonesia. Pemaknaan dalam bahasa waria meliputi antara kata yang dimaknai dengan kata yang memaknai. Kata yang dimaknai sebagai kata yang digunakan untuk mengungkapkan maksud, sedangkan kata yang memaknai adalah kata yang menjadi maksud. Misalnya pada kata "Dendong $><$ Dandan"kata dandan dimakanai dengan kata dendong dan kata dendong memaknai kata dandan begitu pula dengan kata yang lainnya misal saja pada kata "Jelitur $><J e l e k$ ".

Kosakata bahasa waria di atas dapat dinyatakan bahwa dalam penggunaan setiap kosakata yang digunakan bersumber dari kosakata bahasa Indonesia sebagai asal kosakata, bahasa waria diposisikan secara integratif sehingga membentuk suatu pembaharuan kosakata yang dapat menciptakan maksud tertentu. Maksud yang diciptakan dalam bahasa waria menyimpang dari maksud yang telah lazim diketahui dalam bahasa Indonesia. Dengan demikian, penggunaan kosakata bahasa waria hanya komunikatif pada kalangan penggunaannya saja atau kelompok waria yang telah menggunakannya.

\section{Fungsi Penggunaan Bahasa Waria}

Selain sebagai alat komunikasi, bahasa tentunya mempunyai fungsi, seperti halnya bahasa Indonesia. Bahasa Indonesia selain berfungsi sebagai bahasa Nasional atau bahasa pemersatu, di sisi lain bahasa Indonesia juga menunjukkan fungsi dan identitas diri kita sebagai bangsa Indonesia. Demikian juga dengan variasi bahasa waria. Fungsi penggunaan variasi bahasa waria adalah sebagai berikut.

a. Identitas diri dan kelompok

Untuk dapat mengenali seseorang dengan mudah, maka kita memerlukan identitas atau ciri-ciri dari seseorang, tidak terkecuali dengan variasi bahasa waria. Sama seperti bahasa Indonesia yang berfungsi sebagai identitas diri bangsa 
Indonesia, maka variasi bahasa waria juga menunjukkan keberadaan atau eksistensi kaum waria. Bagi sebuah kelompok, identitas juga sama pentingnya, agar masyarakat atau kelompok lain mengenali mereka, baik dari segi bahasa maupun tingkah lakunya sebagai waria. Kaum waria menampakkan dirinya dengan menggunakan bahasa khususnya ketika mereka sedang berkumpul dengan komunitasnya dan saat mereka membicarakan seseorang agar orang tersebut tidak paham dengan apa yang mereka bicarakan. Waria juga sering menggunakan bahasa khususnya untuk membicarakan orang yang mereka sukai dan tidak disukainya, sehingga bagi kaum waria dengan adanya perbedaan bahasa mampu menandakan komunitasnya dan mempunyai bahasa rahasia sendiri yang merupakan penanda identitas diri maupun kelompoknya.

b. Menumbuhkan rasa percaya diri

Bahasa juga mampu menumbuhkan rasa percaya diri seseorang. Bahasa waria dalam komunitasnya selain untuk berinteraksi atau berkomunikasi, bahasa waria juga menumbuhkan rasa percaya diri terhadap diri waria dengan rasa bangga ketika menggunakan atau berkomunikasi dengan bahasa yang mereka miliki.

c. Perubahan sikap

Bahasa pada kalangan waria dinilai mampu merubah sikap diri waria sendiri, dengan menggunakan bahasa khususnya sesama komunitas, mereka merasa lebih berani dan tidak merasa minder dan tingkat kepercayaan diri waria semakin tinggi, bahkan waria memliki jiwa yang lebih dari wanita. Kaum waria berusaha memperjuangkan harkat dan martabat mereka, salah satunya dengan membuat dan mengembangkan bahasa mereka sendiri sehingga menjadikan sikap dan kepercayaan diri yang semakin meningkat.

\section{SIMPULAN}

Berdasarkan hasil penelitian, register bahasa waria di Kabupaten Lombok Timur merupakan varian/ragam bahasa. Bahasa waria hanya digunakan oleh kelompok waria dan orang-orang yang bergaul dan akrab dengan waria. Temuan dalam penelitian ini adalah sebagai berikut: (1) kosa kata berdasarkan klasifikasinya yaitu sumber dan hubungan, (2) makna kosa kata dan, (3) fungsi bahasa waria berdasarkan penggunaannya yaitu sebagai identitas diri dan kelompok, perubahan sikap dan lebih percaya diri serta perasaan bangga menggunakan bahasa waria yang dihimpunkan dari 107 data yang telah dijabarkan berdasarkan klasifikasinya.

\section{DAFTAR PUSTAKA}

Holmes, Janet. 1992. An Introduction to Sociolinguistics. London: Longman.

Pateda, Mansoer. 1992. Sosiolinguistik. Bandung: Angkasa.

Sugiyono. 2013. Metode Penelitian Kuantitatif Kualitatif dan RひD. Bandung: Alfabeta.

Sumarsono. 2012. Sosiolinguistik. Yogyakarta: Pustaka Pelajar. 